Tropical Journal of Pharmaceutical Research July 2015; 14 (7): 1305-1310

ISSN: $1596-5996$ (print); 1596-9827 (electronic)

(C) Pharmacotherapy Group, Faculty of Pharmacy, University of Benin, Benin City, 300001 Nigeria.

All rights reserved.

Available online at http://www.tjpr.org

Review Article

http://dx.doi.org/10.4314/tjpr.v14i7.26

\title{
Role of Endogenous Peptides and Enzymes in the Pathogenesis of Acute Pancreatitis: A Review
}

\author{
Bonam Srinivasa Reddy ${ }^{1,2}$, Sheba Dolly Bonigala ${ }^{1}$ and Vijayapandi Pandy ${ }^{3 *}$ \\ ${ }^{1}$ Department of Pharmacology, Chalapathi Institute of Pharmaceutical Sciences, Guntur 522034, Andhra Pradesh, ${ }^{2}$ Vaccine \\ Immunology Laboratory, Natural Product Chemistry Division, CSIR-Indian Institute of Chemical Technology, Tarnaka, \\ Hyderabad 500007, India, ${ }^{3}$ Department of Pharmacology, Faculty of Medicine, University of Malaya, 50603 Kuala Lumpur, \\ Malaysia
}

*For correspondence: Email: pandiphd@gmail.com; Tel: +60 379674712

Received: 7 February 2015

Revised accepted: 29 May 2015

\begin{abstract}
Acute pancreatitis is an inflammatory disease with the clinical manifestation of acute abdominal pain. Several factors are involved in the pathogenesis of acute pancreatitis. The exact mechanism(s) by which diverse etiological factors induce an attack are still unclear. However, one of the proposed mechanisms for induction of acute pancreatitis is auto-digestion of pancreatic tissues by unwanted activation of pancreatic digestive enzymes. The main objective of this review is to describe the pathogenesis mechanism of acute pancreatitis that are related to various inflammatory and proinflammatory mediators.
\end{abstract}

Keywords: Acute pancreatitis, Pancreatic injury, Cytokines, Chemokines, Inflammation

Tropical Journal of Pharmaceutical Research is indexed by Science Citation Index (SciSearch), Scopus, International Pharmaceutical Abstract, Chemical Abstracts, Embase, Index Copernicus, EBSCO, African Index Medicus, JournalSeek, Journal Citation Reports/Science Edition, Directory of Open Access Journals (DOAJ), African Journal Online, Bioline International, Open-J-Gate and Pharmacy Abstracts

\section{INTRODUCTION}

Acute pancreatitis is an inflammatory disease characterized by varying degrees of endogenous pancreatic injury ranging from a mild oedematous and interstitial process to one which is associated with extensive pancreatic and peripancreatic necrosis. Complications of acute pancreatitis include the development of pancreatic pseudocysts, pancreatic ascites, and vascular changes such as splenic vein thrombosis and development of arterial false aneurysms in the area of the pancreas [1]. The most severe form of acute pancreatitis is severe haemorrhagic and necrotizing pancreatitis, which has been reported to result in mortality rates ranging from 30 to $50 \%$ through liver and lung injury [2]. In particular, liver injury is a clinical prognostic indicator and is incorporated into the various scoring systems used to predict the severity of acute pancreatitis $[2,3]$.

There are several factors influencing the pathogenesis of acute pancreatitis like premature activation of trypsinogen, chemokine production, and pro-inflammatory cytokine production and involvement of cytokine-inducible DNA-binding proteins like signal transducers and activators of transcription (STAT) proteins, latent transcription factors [4]. The synthesis and release of cytokines upon inflammatory action mainly medicated by oxidative stress mechanisms like mitogen activated protein kinases (MAPKs) and nuclear factor-k B (NF-kB) [4].

Free oxygen radicals and pro-inflammatory cytokines which are released by neutrophils and macrophages during acute pancreatitis, 
exacerbate the inflammatory response by causing an increase in local and systemic capillary permeability and by promoting leukocyte adhesion and extravasation [3]. The cellular mechanism of pro-inflammatory cytokines is regulated by nuclear factor-KB (NF-KB) and activator protein-1 (AP-1). NF-KB and AP-1 are two transcriptional complexes required for the early response gene expression of inflammatory molecules [3]. It has been reported that interleukins IL-1b, IL-6, IL-8, and TNF- $\alpha$ levels are significantly increased in both sera and tissues of patients with acute pancreatitis [3]. The main objective of this review is to collect the information about the role of pro-inflammatory cytokines in the development of acute pancreatitis.

\section{Pathophysiology of acute pancreatitis}

Premature activation of digestive enzymes in acinar cells during acute pancreatitis results in auto-digestion of the pancreas. Trypsinogen, a serine protease, is now thought to be the first enzyme to be activated; subsequently other digestive enzymes (chymotrypsinogen and proelastase) are cleaved and activated [5-8]. The pancreas has a variety of self-protective mechanisms to prevent intracellular zymogen activation and subsequent auto-digestion. However in acute pancreatitis, these protective mechanisms are no longer effective or are overwhelmed [5-8]. As a result, the activated pancreatic enzymes destroy the pancreatic cell membranes and subsequently the entire pancreatic tissue, causing pancreatic oedema, vascular damage, haemorrhage, and necrosis. Strong local inflammatory response activates leukocytes and endothelial cells among others. Secreted bioactive molecules from infiltrating leukocytes contribute to local damage and subsequently to the systemic inflammatory response, which may result in multiple organ dysfunction and ultimately death [9]. A number of inflammatory mediators have been implicated in the recruitment of leukocytes into the pancreas [9]. Inflammatory mediators such as substance P and chemokines along with cytokines, interleukins, intercellular adhesion molecules and platelet activating factor have been shown to play significant roles in the pathogenesis of acute pancreatitis [9-11].

\section{Role of substance $P$ in the pathogenesis of} acute pancreatitis

Substance $P$ is an 11-amino acid neuropeptide that was originally isolated and purified by Chang and Leeman from bovine pituitary glands [12]. It is a member of the tachykinin family and has been shown to induce rapid smooth muscle contraction in guinea pig ileum and rat duodenum [12].

Studies have indicated that substance $P$ by acting through neurokinin 1 receptor (NK1R) stimulates pancreatic acinar cells to release chemokines MCP-1, MIP-1a, MIP-2 and RANTES by PLC- dependent mechanisms (Figure 1). The released chemokines acting via chemokine receptors facilitate the release of cytokines (IL-1, IL-8 and TNF- $\alpha$ ) as shown in Figure 2, which play an important role in the pathogenesis of acute pancreatitis [11,13-15]. Both genetic deletion of NK1R and blockade of NK1R with its selective antagonist CP96345, protected mice against acute pancreatitis and associated lung injury $[11,16]$. Substance $P$ has also been shown to play an important role in the pathogenesis of asthma, inflammatory bowel disease and arthritis $[17,18]$. Substance $P$ levels in the pancreas and NK1R expression on pancreatic acinar cells are increased during secretagogue-induced experimental pancreatitis $[11,14,15,19]$. It has been suggested that the neuropeptide substance $\mathrm{P}$ plays an important role in the evolution of pancreatic inflammatory diseases such as acute pancreatitis [11]. These observations indicate that substance $\mathrm{P}$, acting through NK1R, plays an important proinflammatory role in regulating the severity of acute pancreatitis. Substance $P$ also induces an increase in $\left[\mathrm{Ca}^{2+}\right]_{i}$ which results in the phosphorylation of $\mathrm{PKC \alpha / \beta II,} \mathrm{ERK} \mathrm{and} \mathrm{JNK;}$ leading to the activation of NF-KB p65, AP-1, cJun and ultimately to chemokine production [20]. However, the exact mechanism(s) by which substance $P$ contributes to the pro-inflammatory signalling in acute pancreatitis is not completely understood [20].

\section{Role of chemokines in the pathogenesis of acute pancreatitis}

Chemokines are a family of small (8-10 kDa) inducible cytokines with activating and chemotactic effects on leukocyte subsets. These proteins are defined by four invariant cysteine residues and are classified into four sub-families (two major and two minor) based on the relative position of the first two cysteine residues: CXC ( $\alpha$-subfamily), CC ( $\beta$-subfamily), C ( $\gamma$-subfamily) and $\mathrm{CX} 3 \mathrm{C}$ ( $\delta$-subfamily) chemokines ( $\mathrm{C}$ stands for cysteine and $X$ stands for other amino acids) [21]. 


\section{Substance P (RPKPQQFFGLM-NH2)}

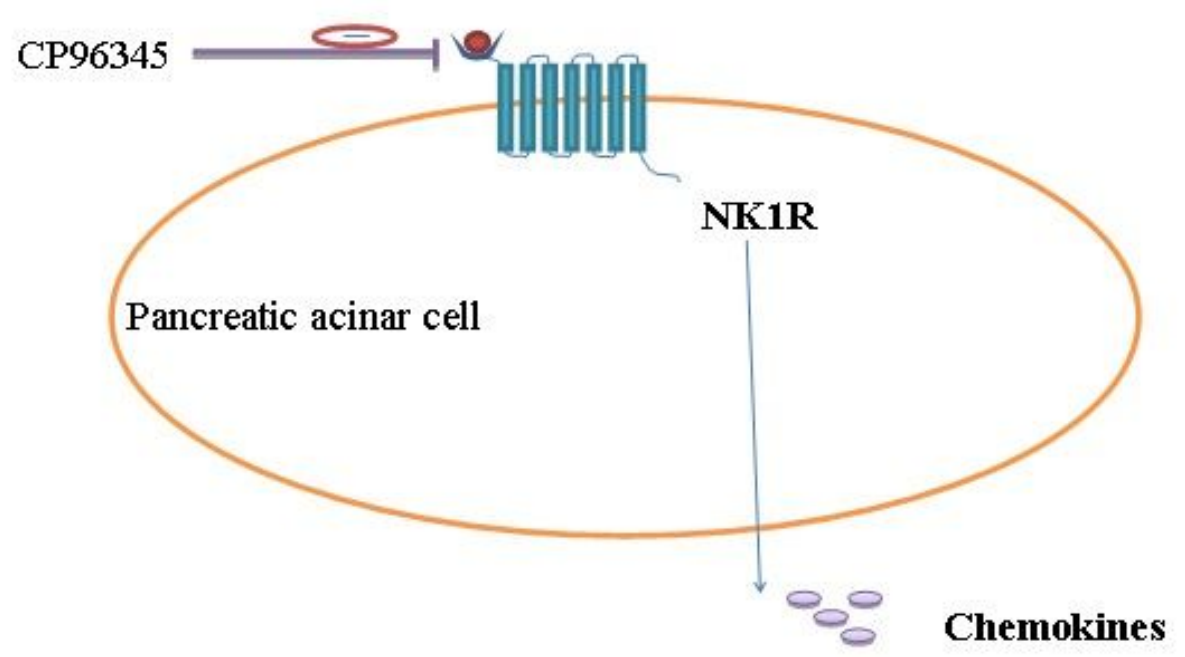

Figure 1: Induction of chemokines by substance $P$ in the pancreatic acinar cells

The two major subfamilies $\mathrm{CC}$ and $\mathrm{CXC}$ chemokines have been extensively investigated in various disease conditions including acute pancreatitis.

Chemokines act as regulators of immune, inflammatory and hematopoietic processes. They play a major role in leukocyte trafficking, recruitment and recirculation. The $\mathrm{CC}$ chemokine family members include monocyte chemoattractant protein- 1 (MCP-1), MCP-2, macrophage inflammatory protein; MIP-1a, MIP1b, RANTES, eotaxin and thymus- and activation-regulated chemokine (TARC). The CC chemokines serves as chemoattractant for monocytes/macrophages, activated T-cells, Bcells, eosinophils, basophils and dendritic cells. [22,23].

A study of chemokine gene expression in rat pancreatic acinar cells showed an up-regulated rat CXC chemokine mob-1 and $\mathrm{CC}$ chemokine MCP-1 mRNA expression within $1 \mathrm{~h}$ of ceruleininduced acute pancreatitis in vivo. The mob-1 mRNA was also induced by either retrograde injection of bile salts or cerulein in acinar cells in vitro $[24,25]$. An in vitro study on cholecystokinin (CCK)- and ethanol-treated rat pancreatic acinar cells demonstrated that rat pancreatic acinar cells secreted MCP-1 and RANTES in response to $\mathrm{CCK}$ and ethanol stimulation, suggesting a role for these two chemokines in the pathogenesis of acute pancreatitis [26]. It has also been shown that cerulein hyper-stimulation induced synthesis of MCP-1 but not CINC in rat pancreatic acinar cells [9]. This MCP-1 synthesis is mediated through a calcium-dependent mechanism involving NFKB activation.
The role of MCP-1 as well as two other CC chemokines MIP-1 $\alpha$ and MIP-1 $\beta$ has been extensively evaluated in human acute pancreatitis. It was found that complicated acute pancreatitis is associated with significantly elevated levels of local and systemic concentrations of MCP-1 and MIP-1a [27]. A close correlation between the severity of remote organ failure and the degree of MCP-1 elevation suggests that MCP-1 might play a pivotal role in the pathological mechanism of complicated human acute pancreatitis [27]. MCP-1 is believed to contribute to the progression of chronic pancreatitis which results from repetitive pancreatic injury with sustained production of various pro-inflammatory cytokines and chemokines through monocyte/macrophage recruitment [28]. Moreover, it has been reported that blockade of MCP-1 could reduce the development of pancreatic fibrosis in chronic pancreatitis [29].

Role of nuclear factor $K B$ (NFKB) in the pathogenesis of acute pancreatitis

NFkB activation is a key mediator of the inflammatory response in acute pancreatitis [3033]. It is an ubiquitous transcription factor which is implicated in the regulation of many genes that code for mediators of the immune and acute phase of inflammatory responses [34]. In a classical pathway, NFKB is sequestered in the cytoplasm of most resting cells through its association with an inhibitory protein called IKB. During stimulation by IL-1 or TNF- $\alpha$, a whole cascade of adaptor proteins and protein kinases are activated, leading to the phosphorylation of IKB by the IKB kinases $\alpha$ and $\beta(\mathrm{IKK} \alpha / \beta)$ [35]. 


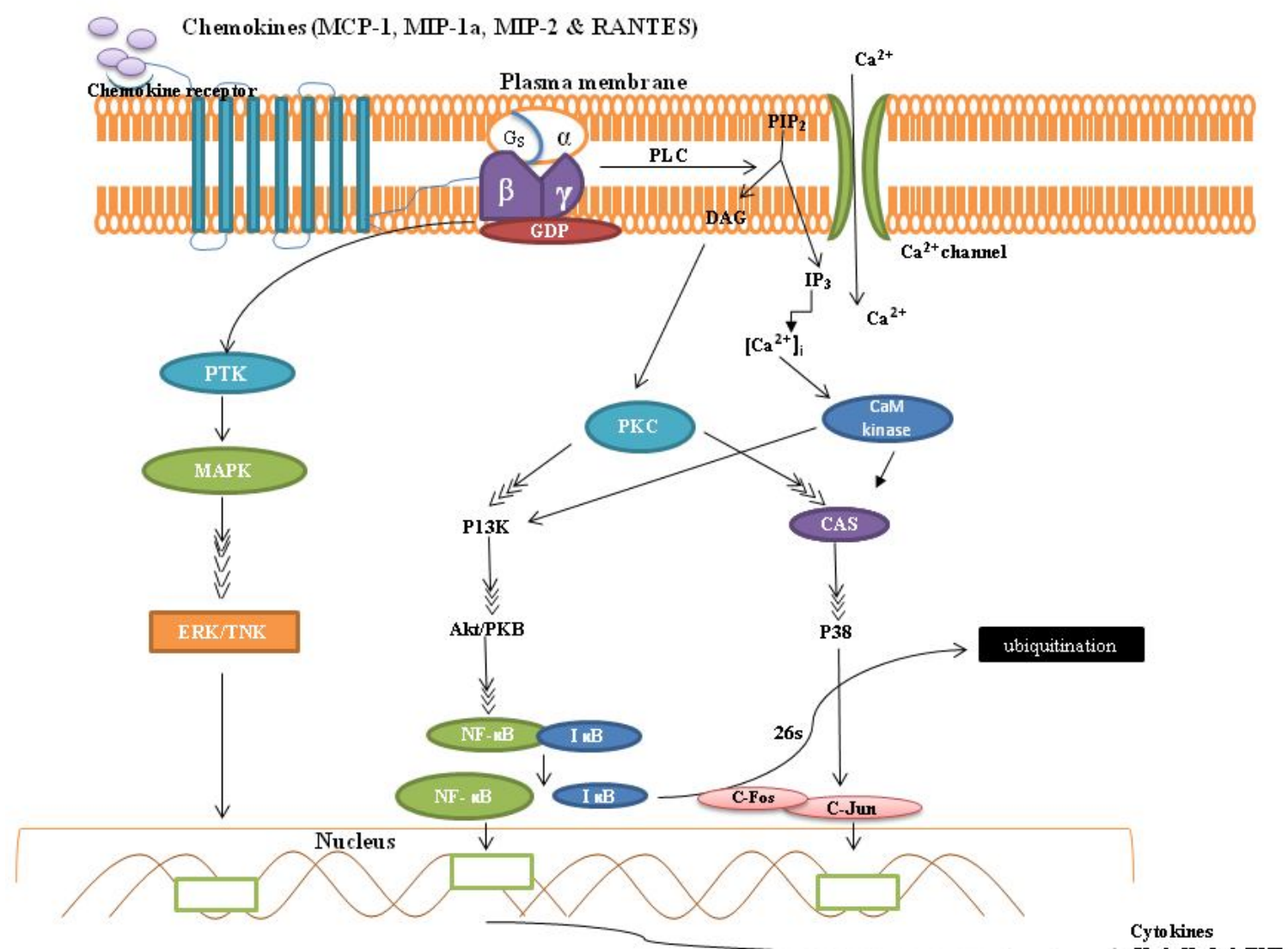

Figure 2: Downhill mechanism of cytokines secretion, as a result of chemokine receptor activation. CAS: Crkassociated substrate; ERK- Extracellular signal-regulated kinases; PTK- Protein tyrosine kinases; CaM kinase, $\mathrm{Ca}^{2+} /$ calmodulin-dependent kinases

This depends on the regulatory protein NEMO/ IKK y (NFKB essential modifier) associated with the complex containing two kinases, IKK $\alpha$ and IKK $\beta[36,37]$.

Once phosphorylated, IKB is ubiquitinated and subsequently degraded through 26S proteasome. Consequently, NFKB is freed to migrate into the nucleus, and binds to its consensus decameric sequence located in the promoter region of several genes involved in the pro-inflammatory response, encoding various immunoreceptors, cell adhesion molecules, cytokines and chemokines [34].

The first report in 2005 by Meng et al, demonstrated the effect of resveratrol on nuclear factor Kappa-B (NF-KB) and the inflammatory response in a rat model of severe acute pancreatitis. The rats treated with resveratrol were reported to have significantly lower levels of NF-KB, Tumour Necrosis Factor- $\alpha$ (TNF- $\alpha$ ), and Interleukin-8 (IL-8) expressions compared to control animals. Moreover, histological examination of the pancreas showed less hyperaemia, necrosis, and oedema in the treated group [38].
Role of activator protein-1 (AP-1) in the pathogenesis of acute pancreatitis

AP-1 expression is induced by multiple stimuli such as inflammatory cytokines, mitogenic growth factors, phorbol esters, oncogenes and cellular stress among others. It is activated during the cell cycle to promote cell survival, differentiation and adaptive responses.

$\mathrm{NF}-\mathrm{KB}$ and AP-1 regulate many gene expressions which participate in immune and inflammatory responses. NF-KB is found in an inactive form in the cell cytoplasm attached to inhibitor protein kappa B (IKB). When activated, IKB is phosphorylated by specific IKK kinases and rapidly degraded though proteasomedependent pathways. The other transcription factor, AP-1 is a homo- or heterodimer complex molecule formed from Jun, Fos or the activating transcription factor subunits [3]. AP-1 is also involved in tissue proliferation, differentiation and transformation as observed in adult tissues and plays a key role in the regulation of the inflammatory process. AP-1 can be activated by growth factors, cytokines, chemokines, hormones and multiple environmental factors [3]. 


\section{Mitogen-activated protein kinases (MAPKs)}

MAPKs are a family of serine/threonine kinases activated by a cascade of intracellular phosphorylation events and transduce signals from the cell surface to the nucleus $[39,40]$. There are three well-characterized sub-families of MAPKs that control an array of physiological processes. It is generally believed that ERKs function in the control of cell division and Jun- $\mathrm{N}$ terminal kinases (JNKs) are critical regulators of transcription and p38 MAPKs are activated by inflammatory cytokines and environmental stress [41].

\section{CONCLUSION}

The current review describes the various inflammatory mediators that influence the pathogenesis of acute pancreatitis. Acinar cell injury by trypsinogen activation plays a critical role in the pathogenesis mechanism of acute pancreatitis. The severity of cell death depends on the level of both pro-inflammatory and inflammatory mediators which involve the development of both apoptosis and necrotic pancreatic cell death. It is hoped that this review will assist investigators to better understand the mechanisms involved in the pathogenesis of acute pancreatitis and thus facilitate the development of more effective therapeutic molecules to treat acute pancreatitis.

\section{ACKNOWLEDGEMENT}

The authors are grateful to University of Malaya for providing financial assistance (UMRG Grant no. RG495-13HTM) to one of the authors (V.P.).

\section{REFERENCES}

1. Michael LS. Relationship between pancreatitis and lung diseases. Respiration Physiology 2001; 128(1): 1316.

2. Scott FG, Yang J, Kathryn B, Krista H, Heather CPK. Epling-Burnette, Yanhua $P$, James $N$, Michel MM. Acute Pancreatitis Induces FasL Gene Expression and Apoptosis in the Liver. J Surg Res 2004; 122(2): 201-209.

3. Gulcubuk A, Haktanir D, Cakiris A, Ustek D, Guzel O, Erturk M, Karabagli M, Akyazi I, Cicekci $H$, Altunatmaz K, Uzun H, Ates K. Effects of curcumin on proinflammatory cytokines and tissue injury in the early and late phases of experimental acute pancreatitis. Pancreatol 2013; 13(4): 347-354.

4. Yubero S, Ramudo L, Manso MA, De Dios I. The role of redox status on chemokine expression in acute pancreatitis. Biochim Biophys Acta 2009; 1792(2): 148-154.

5. Steer ML. Early events in acute pancreatitis. Baillieres Best Pract Res Clin Gastroenterol 1999; 13(2): 213225.

6. Gorelick FS, Otani T. Mechanisms of intracellular zymogen activation. Baillieres Best Pract Res Clin Gastroenterol 1999; 13(2): 227-240.

7. Grady T, Mah'Moud M, Otani T, Rhee S, Lerch MM, Gorelick FS. Zymogen proteolysis within the pancreatic acinar cell is associated with cellular injury. Am J Physiol 1998; 275(5): 1010-1017.

8. Saluja AK, Lee HS, Bhatia M, Frossard JL, Steer ML. Secretagogue- induced digestive enzyme activation and cell injury in rat pancreatic acini. Am J Physiol 1999; 276(4): 835-842.

9. Bhatia $M$, Brady $M$, Shokuhi $S$, Christmas $S$, Neoptolemos JP, Slavin J. Inflammatory mediators in acute pancreatitis. J Pathol. 2000; 190(2): 117-125.

10. Bhatia $M$, Ramnath RD, Chevali L, Guglielmotti A. Treatment with bindarit, a blocker of MCP-1 synthesis, protects mice against acute pancreatitis. Am J Physiol Gastrointest Liver Physiol 2005; 288(6): 1259-1265.

11. Bhatia M, Saluja AK, Hofbauer B, Frossard JL, Lee HS, Castagliuolo I, Wang CC, Gerard N, Pothoulakis C, Steer ML. Role of substance $P$ and the neurokinin 1 receptor in acute pancreatitis and pancreatitisassociated lung injury. Proc Natl Acad Sci USA 1998; 95(8): 4760-4765.

12. Chang MM, Leeman SE. Isolation of a sialogogic peptide from bovine hypothalamic tissue and its characterization as substance P. J Biol Chem. 1970; 245(18): 4784-4790.

13. Bhatia M, Slavin J, Cao Y, Basbaum Al, Neoptolemos JP. Preprotachykinin-A gene deletion protects mice against acute pancreatitis and associated lung injury. Am J Physiol Gastrointest Liver Physiol 2003; 284(5): 830-836.

14. Patto RJ, Vinayek R, Jensen RT, Gardner JD. Carbachol does not down- regulate substance $P$ receptors in pancreatic acini. Pancreas 1992; 7(4): 447-452.

15. Sjodin L, Gylfe E. A selective and potent antagonist of substance $P$ receptors on pancreatic acinar cells. Biochem Int 1992; 27(1): 145-153.

16. Lau HY, Wong FL, Bhatia M. A key role of neurokinin 1 receptors in acute pancreatitis and associated lung injury. Biochem Biophys Res Commun 2005; 327(2): 509-515.

17. Bowden JJ, Garland AM, Baluk P, Lefevre P, Grady EF, Vigna SR, Bunnett NW, McDonald DM. Direct observation of substance $P$-induced internalization of neurokinin 1 (NK1) receptors at sites of inflammation. Proc Natl Acad Sci USA 1994; 91(19): 8964-8968.

18. Thurgston G, Baluk $P$, Hirata A, McDonald DM. Permeability-related changes revealed at endothelial cell borders in inflamed venules by lectin binding. Am J Physiol 1996; 271(6): 2547-2562.

Trop J Pharm Res, July 2015; 14(7): 1309 
19. Jensen RT, Jones SW, Lu YA, Xu JC, Folkers K, Gardner $J D$. Interaction of substance $P$ antagonists with substance $P$ receptors on dispersed pancreatic acini. Biochim Biophys Acta 1984; 804(2): 181-191.

20. Ramnath RD, Sun J, Bhatia M. Role of calcium in substance P-induced chemokine synthesis in mouse pancreatic acinar cells. Br J Pharmacol 2008; 154(6): 1339-1348.

21. Zlotnik A, Yoshie O. Chemokines: a new classification system and their role in immunity. Immunity 2000; 12(2): 121-127.

22. Baggiolini M, Loetscher $P$, Moser B. Interleukin-8 and the chemokine family. Int J Immunopharmacol 1995; 17(2): 103-108.

23. Wells TN, Power CA, Lusti-Narasimhan M, Hoogewerf AJ, Cooke RM, Chung CW, Peitsch MC, Proudfoot $A E$. Selectivity and antagonism of chemokine receptors. J Leukoc Biol 1996; 59(1): 53-60.

24. Grady T, Liang P, Ernst SA, Logsdon CD. Chemokine gene expression in rat pancreatic acinar cells is an early event associated with acute pancreatitis. Gastroenterol 1997; 113(6): 1966-1975.

25. Han $B$, Logsdon $C D$. Cholecystokinin induction of mob-1 chemokine expression in pancreatic acinar cells requires NF-kappaB activation. Am J Physiol 1999; 277(1): 74-82.

26. Yang BM, Demaine AG, Kingsnorth A. Chemokines $M C P-1$ and RANTES in isolated rat pancreatic acinar cells treated with CCK and ethanol in vitro. Pancreas 2000; 21(1): 22-31.

27. Rau B, Baumgart K, Krüger CM, Schilling M, Beger HG. CC-chemokine activation in acute pancreatitis: enhanced release of monocyte chemoattractant protein-1 in patients with local and systemic complications. Intensive Care Med 2003; 29(4): 622629.

28. Ohashi S, Nishio A, Nakamura H, Asada M, Tamaki H, Kawasaki K, Fukui T,Yodoi J, Chiba $T$. Overexpression of redox-active protein thioredoxin1 prevents development of chronic pancreatitis in mice. Antioxid Redox Signal 2006; 8(9): 1835-1845.

29. Zhao HF, Ito T, Gibo J, Kawabe K, Oono T, Kaku T, Arita Y, Zhao QW, Usui M, Egashira K, Nawata H. Anti- monocyte chemoattractant protein 1 gene therapy attenuates experimental chronic pancreatitis induced by dibutyltin dichloride in rats. Gut 2005; 54(12): 1759-1767.

30. Chen X, Ji B, Han B, Ernst SA, Simeone D, Logsdon CD. $N F-K B$ activation in pancreas induces pancreatic and systemic inflammatory response. Gastroenterol 2002; 122(2): 448-457.

31. Jaffray C, Yang J, Carter G, Mendez C, Norman J. Pancreatic elastase activates pulmonary nuclear factor $\kappa B$ and inhibitory $\kappa B$, mimicking pancreatitisassociated adult respiratory distress syndrome. Surgery 2000; 128(2): 225-231.

32. Satoh A, Shimosegawa $T$, Fujita $M$, Kimura $K$, Masamune A, Koizumi M, Toyota T. Inhibition of nuclear factor- $K B$ activation improves the survival of rats with taurocholate pancreatitis. Gut 1999; 44(2): 253-258.

33. Steinle AU, Weidenbach $H$, Wagner M, Adler G, Schmid $R M$ (1999) NF-KB /Rel activation in cerulein pancreatitis. Gastroenterol 1999; 116(2): 420-430.

34. Baeuerle PA, Baichwal VR. NFKB as a frequent target for immunosuppressive and anti-inflammatory molecules. Adv Immunol 1997; 65: 111-137.

35. Karin M. The beginning of the end: IKB kinase (IKK) and NFKB activation. J Biol Chem 1999; 274: 2733927342.

36. Akira S, Takeda K. Toll-like receptor signalling. Nat Rev Immuno 2004; 4: 499-511.

37. Hayden MS, Ghosh S. Signaling to NF-kappa B. Genes Dev 2004; 18(8): 2195-2224.

38. Meng Y, Ma QY, Kou XP, Xu J. Effect of resveratrol on activation of nuclear factor kappa-B and inflammatory factors in rat model of acute pancreatitis. World $\mathrm{J}$ Gastroenterol. 2005; 11: 525-528

39. Chang L, Karin M. Mammalian MAP kinase signalling cascades. Nature 2001; 410: 37-40.

40. Dong C, Davis RJ, Flavell RA. MAP kinases in the immune response. Annu Rev Immunol 2002; 20: 5572.

41. Hazzalin C, Mahadevan LC. MAPK-regulated transcription: a continuously variable gene switch? Nat Rev Mol Cell Biol 2002; 3(1): 30-40. 